\title{
Growth pattern and prevalence of obesity in affluent schoolchildren of Delhi
}

\author{
A Sharma*, K Sharma and KP Mathur \\ Nutrition Foundation of India, C-13, Qutab Institutional Area, New Delhi - 110016, India
}

Submitted 2 June 2005: Accepted 9 March 2006

\begin{abstract}
Objective: To investigate the prevalence of obesity in affluent schoolchildren of Delhi. Design: This was a cross-sectional study covering over 4000 students. Anthropometric measurements and birth weights of all the students were recorded.

Setting and subjects: The study was carried out in a school catering to the affluent section of Indian society and included both boys and girls in the age range 4 to 17 years. Results: The heights and weights of the children were almost similar to those of the National Center for Health Statistics standards, and were much above the values reported by the Indian National Nutrition Monitoring Bureau, which largely captures rural children belonging to lower socio-economic strata in India. Of the subjects studied, $22 \%$ were overweight and $6 \%$ were obese. Only $6 \%$ of these children had low birth weight.

Conclusion: The prevalence of obesity is rising among children because of their change in lifestyle. Children born with a birth weight of $\geq 3 \mathrm{~kg}$ tended to have higher body mass index in their adolescent years and maybe consequently in their adult years. Nutrition education can play an important part in reducing the incidence of overweight/obesity and its associated complications.
\end{abstract}

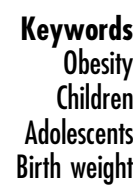

The World Health Organization (WHO) defines obesity as a 'global epidemic'. It is now estimated that there are more than 100 million obese individuals worldwide $^{2}$. Gopinath et al. estimated the obesity prevalence in an adult urban population of Delhi at $27.8 \% \%^{3}$. A recent study in the UK showed that more than 55\% of adults are overweight (body mass index (BMI) $>25 \mathrm{~kg} \mathrm{~m}^{-2}$ ), while $20 \%$ are obese $\left(\mathrm{BMI}>30 \mathrm{~kg} \mathrm{~m}^{-2}\right)^{4}$. A study conducted by the Nutrition Foundation of India among the urban upper middle class segment in Delhi showed obesity in $32.2 \%$ of males and $50.0 \%$ of females 5 . In another study based on BMI, Misra et al. showed that obesity was more prevalent in females (15.6\%; 95\% confidence interval (CI) 10.7-22.3) than in males $\left(13.3 \%\right.$; 95\% CI 8.5-19.5) ${ }^{6}$.

The two most important factors that contribute to a sudden increase in incidence of obesity are changes in dietary practices and urbanisation. Presently, there is inclusion of more fats and oils, more sugar and less fibre in the diets of people $e^{5}$. Convenience foods and fast foods have found increasing acceptance. Apart from dietary changes, changes in occupational activity, sedentary lifestyles and a lack of adequate physical activity have also been observed, which in turn have contributed to the increased incidence of obesity. Occupations that involve heavy manual labour are increasingly being replaced by sedentary jobs.
Obesity is associated with several risk factors for heart disease and other chronic diseases in adult life, including hyperlipidaemia, hyperinsulinaemia, hypertension and early atherosclerosis ${ }^{7}$. It is an important factor contributing to the morbidity and mortality due to chronic noncommunicable diseases.

The pace of developmental transition in Third World countries has been particularly marked in recent times, and has led to the 'double burden' of undernutrition and obesity in developing countries. It is therefore imperative that the rising incidence of obesity is controlled before it emerges as the single most important public health problem in India.

The global prevalence of childhood obesity is also increasing very rapidly ${ }^{1}$. The number of seriously overweight children and adolescents has more than doubled in the last three decades ${ }^{8}$. In developed countries, obesity in children and adolescents is widely prevalent. It is estimated that almost $30 \%$ of children and teenagers are overweight and the numbers appear to be rising. An overweight adolescent has a 70\% chance of becoming an obese adult, and obesity can lead to a higher risk of lifethreatening health problems. In other words, adolescent obesity significantly increases the odds of the adult comorbidities 8 .

Childhood obesity is associated with increased risk of gallbladder disease, osteoarthritis, hypertension, 
dyslipidaemias and sleep apnoea. In adolescence, obesity is likely to be associated with various psychological consequences. Apart from the physical risks, overweight children can exhibit emotional ramifications secondary to ridicule and labelling by their peers, including lower levels of self-esteem.

Common causes of weight gain are eating large portions of food (more than the recommended intake for a particular age and sex based on the nature of work), frequent consumption of food, eating fried and junk foods, using chocolate etc. as a reward and eating while viewing television, which affects the physical activity of children. Usually, fast foods are high in cholesterol, sugar, sodium, additives and preservatives, which cause chronic degenerative disorders. They have very low contents of fibre, minerals, vitamins and antioxidants, thereby increasing the vulnerability to heart attacks, cancer and diabetes.

Childhood obesity is not confined to industrialised countries, as high rates are already evident in some developing nations ${ }^{1}$. In India, it has been reported that childhood obesity is more common in Delhi and Punjab $^{9}$. A study carried out in a school in Chandigarh, where the children came from an affluent background, showed that $52 \%$ of boys and $44 \%$ of girls were obese $^{9}$. In Australia, the prevalence of overweight and obesity in childhood is approximately $25 \%{ }^{10}$. In the USA, one child in every five is overweight ${ }^{11}$ and the recent NHANES (National Health Examination Survey) study showed that $12-14 \%$ of children are obese ${ }^{12}$. It has been observed that family size is inversely related to childhood obesity ${ }^{12}$. In a meticulous analysis of children who were followed from birth through their early adulthood, researchers found that heavy mothers give birth to bigger babies who later become obese adults $^{13}$.

The present study was carried out among children and adolescents belonging to upper socio-economic groups in the state of Delhi. The objectives of the study were to:

- assess the anthropometric status of children and adolescents aged 4-17 years in a public school catering to children from the upper socio-economic strata of Indian society;

- compare the growth patterns of these children with those of the US National Center for Health Statistics (NCHS) reference population and Indian National Nutrition Monitoring Bureau (NNMB) data, which largely captures rural children belonging to lower socio-economic strata in India;

- assess the prevalence of obesity in the affluent children;

- find the prevalence of low birth weight among the affluent children; and

- study the relationship, if any, between birth weight and subsequent growth performance.

\section{Methods and subjects}

The present cross-sectional study was carried out in a Delhi school catering to the upper strata of Indian society. The duration of the study was 3 years. The total sample size was over 4000 children in the age group 4-17 years. Efforts were made to collect information on equal numbers of boys and girls in each age group calculated at the difference of one year (Table 1). Almost all children were from affluent sections of society. Of the total number of subjects, only $0.5 \%$ lived in joint families (with grandparents).

In total 4399 children were covered in the study, of whom $56.7 \%$ were boys and $43.3 \%$ were girls in various age groups ranging from 4 to 17 years. Efforts were made to cover the maximum possible number of students in each grade.

A proforma was designed to collect information on family background, birth weight and anthropometric measurements, including standing height, weight, mid upper-arm circumference (MUAC) and triceps skinfold thickness (TSF). The study team included both male and female trained workers.

\section{Antbropometry}

Anthropometric measurements were taken using standard techniques and instruments ${ }^{14}$ : a Microtoise anthropometer for height (to the nearest $\mathrm{mm}$ ), a Seca solar digital balance for weight (to the nearest $100 \mathrm{~g}$ ), a fibreglass tape for MUAC (to the nearest $\mathrm{mm}$ ) and Harpenden callipers for TSF (to the nearest $\mathrm{mm}$ ). Standard precautions were taken to ensure instrument validity, and calibration and quantification of intra- and inter-person errors were performed from time to time.

The median heights and weights of subjects in the present study were compared with datasets from the $\mathrm{NCHS}^{15}$ and $\mathrm{NNMB}^{16}$. TSF data of the present study were compared with NNMB (4-17 years) and NCHS (9-17 years) data. MUAC data of the present study were

Table 1 Distribution of the study subjects according to age

\begin{tabular}{lcrc}
\hline Age (years) & Boys $(n)$ & Girls $(n)$ & Total $(n)$ \\
\hline 4 & 127 & 93 & 220 \\
5 & 110 & 93 & 203 \\
6 & 152 & 109 & 261 \\
7 & 131 & 86 & 217 \\
8 & 129 & 118 & 247 \\
9 & 166 & 103 & 269 \\
10 & 268 & 212 & 480 \\
11 & 271 & 188 & 459 \\
12 & 244 & 203 & 447 \\
13 & 207 & 152 & 359 \\
14 & 185 & 136 & 321 \\
15 & 207 & 179 & 386 \\
16 & 203 & 156 & 359 \\
17 & 97 & 74 & 171 \\
Total & 2497 & 1902 & 4399 \\
\hline
\end{tabular}


compared with NNMB (4-17 years) data only, as the NCHS does not have MUAC standards for the age group studied.

After careful examination of available worldwide data, a WHO expert working group constituted to advise upon the use of anthropometric indicators of nutritional status recommended that the NCHS data are best suited for use as an international reference, since they meet most of the criteria necessary for this purpose. The NCHS data are based on growth measurements of a large number of American children and are currently used widely for reference purposes in many countries, including India.

The Indian Council of Medical Research established the NNMB in seven Indian states. The NNMB carries out diet and nutrition surveys in these seven states (100-200 villages in each state). Thus, in total, about 60500 individuals (13500 households) are covered in the NNMB dataset.

\section{Birth weight}

The birth weight of all of the children was obtained from the parents. This was based on their recollection and, if required, the parents checked the birth weight against the birth record.

\section{Data analysis}

The data were analysed to determine median values of anthropometry of boys and girls in 1-year age groups, and compared with the median values of NCHS and NNMB datasets. BMI was calculated for each child from measured from weight and height, and the frequencies of normal weight, overweight and obesity were determined in the total sample and in boys and girls separately for different age groups. The distribution of boys and girls in different birth weight categories according to present BMI was obtained. Correlation coefficients were calculated to investigate the association between subjects' birth weight and present BMI. The software package SPSS version 10.0 (SPSS Inc.) was used for statistical analyses.

\section{Results}

\section{Weight and beight}

The median weights and heights of boys and girls in the present study are compared with corresponding NCHS and NNMB data for different ages in Figs 1-4.

Both boys and girls in the present study were much heavier and taller compared with corresponding median figures from the NNMB dataset (rural children). At 17 years, the difference in weight between children in the present study and rural children was over $17 \mathrm{~kg}$ for boys and approximately $12 \mathrm{~kg}$ for girls; the corresponding difference in height was about $10 \mathrm{~cm}$ in boys and $8 \mathrm{~cm}$ in girls.

Generally, both boys and girls in the present study were also heavier and taller compared with NCHS data for corresponding age groups. In boys, the difference in

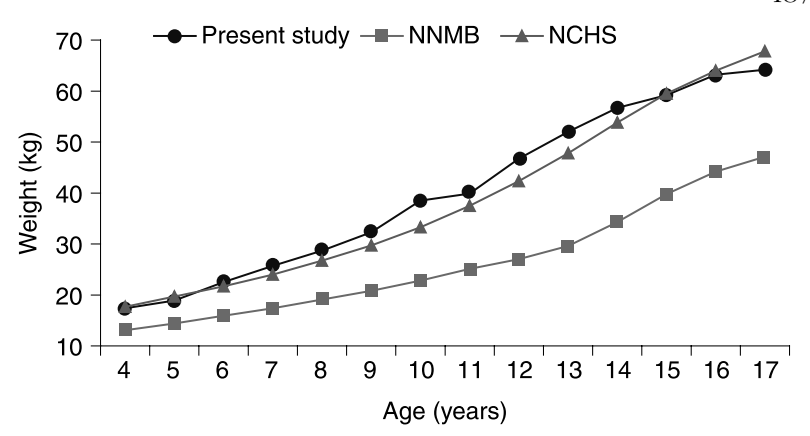

Fig. 1 Comparison of the weight of affluent boys in the present study with the US National Center for Health Statistics (NCHS) reference and Indian National Nutrition Monitoring Bureau (NNMB) data

weight increased steadily to reach a maximum at age of 10 years, then the difference narrowed, and by the age of 17 years the NCHS reference population was heavier than the present one. Similarly, in girls, the maximum difference was observed at the age of 11 years, then the difference narrowed, and from 12 years onwards the NCHS weight values were higher than the present ones. Towards the end of the teenage years, a levelling off of weight could be seen in both boys and girls.

In the case of height, the data of the present study were comparable to those of the NCHS in both boys and girls. Boys in the present study were taller than those of the NCHS reference population until age 13 years. The difference between the two values increased steadily until 10 years and then declined, so that the NCHS values were higher after 14 years. Similarly, among girls, the NCHS values overtook the present values from age 12 years onwards.

The difference in height (between NCHS and the present study) was not as large as the difference in weight. However, for height also there was a levelling off in both boys and girls at 16-17 years in all the three studies.

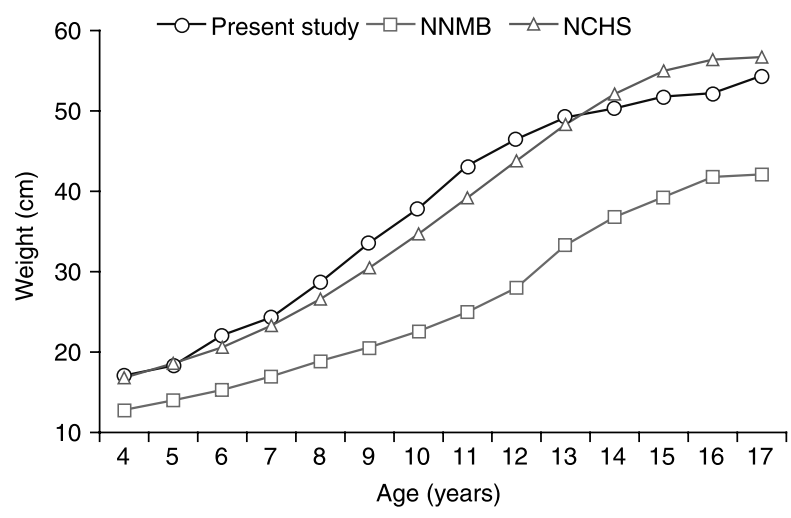

Fig. 2 Comparison of the weight of affluent girls in the present study with the US National Center for Health Statistics (NCHS) reference and Indian National Nutrition Monitoring Bureau (NNMB) data 
488

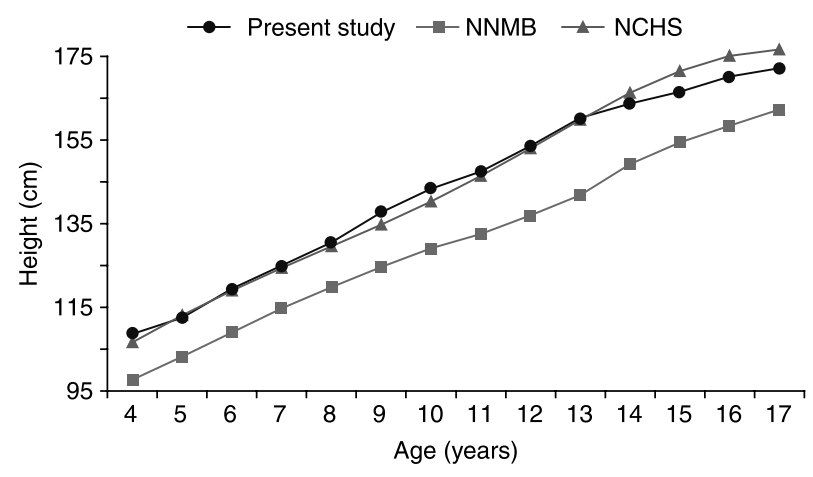

Fig. 3 Comparison of the height of affluent boys in the present study with the US National Center for Health Statistics (NCHS) reference and Indian National Nutrition Monitoring Bureau (NNMB) data

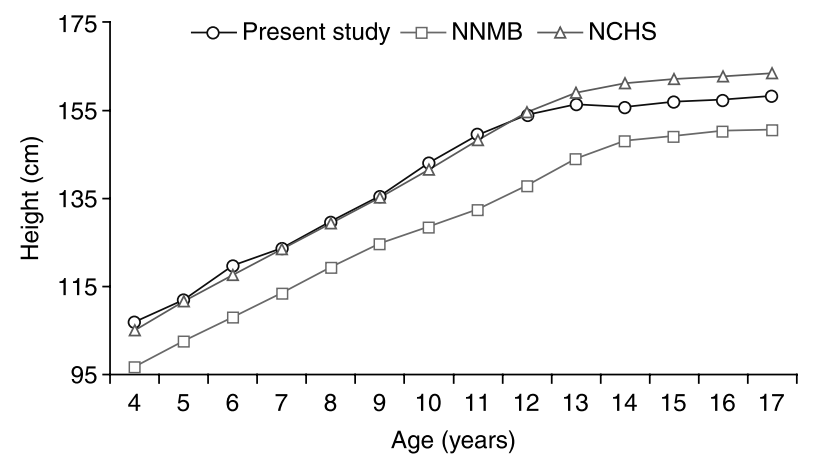

Fig. 4 Comparison of the height of affluent girls in the present study with the US National Center for Health Statistics (NCHS) reference and Indian National Nutrition Monitoring Bureau (NNMB) data

The present study reveals that the growth performance of affluent Indian children mainly corresponds to NCHS data and in fact even exceeds it at some points.

\section{Sitting beight, MUAC and TSF}

Figures 5-8 show the median sitting height, MUAC and TSF values of the present study and the comparison with NCHS and NNMB data where applicable.

The median sitting height of boys was greater than that of the girls in almost all age groups. In the category 10-12 years, girls showed a slight increase compared with boys.

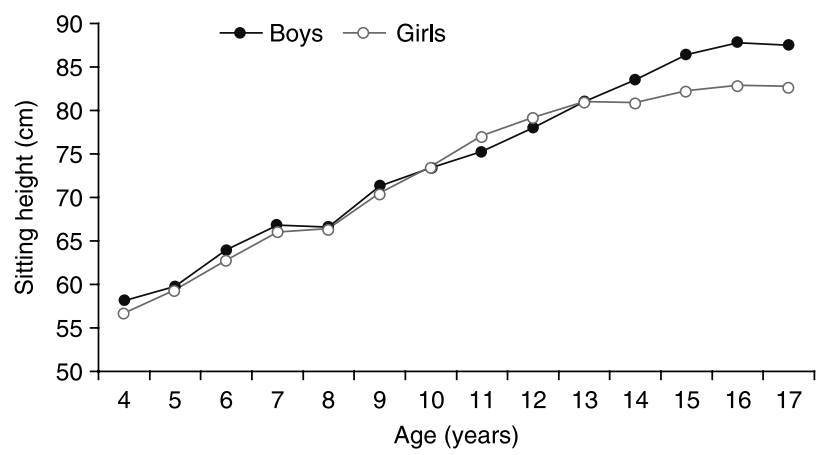

Fig. 5 Comparison of the sitting height of affluent boys and girls in the present study

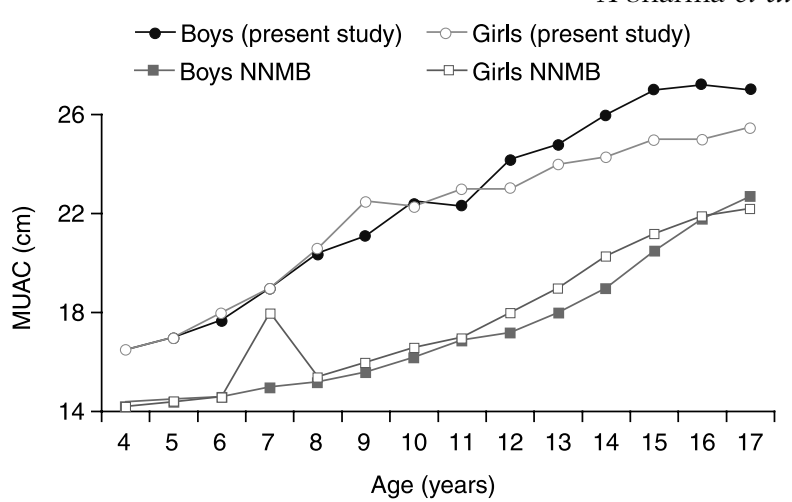

Fig. 6 Comparison of the mid upper-arm circumference (MUAC) of affluent boys and girls in the present study with Indian National Nutrition Monitoring Bureau (NNMB) data

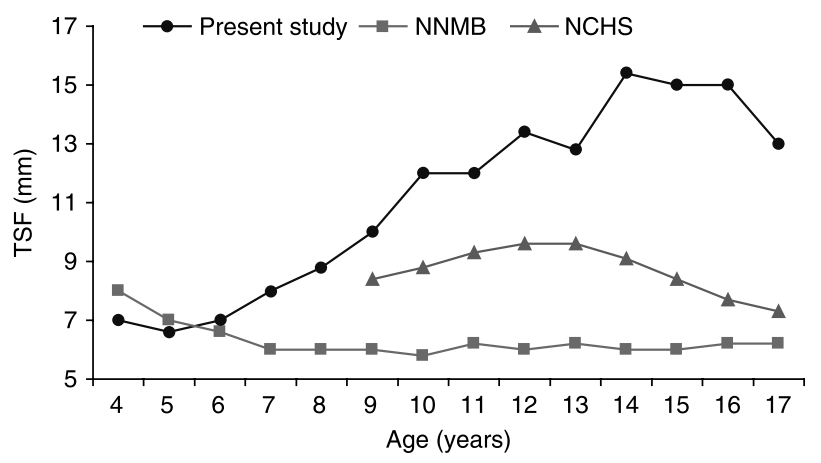

Fig. 7 Comparison of the triceps skinfold thickness (TSF) of affluent boys in the present study with the US National Center for Health Statistics (NCHS) reference and Indian National Nutrition Monitoring Bureau (NNMB) data

From the age of 14 years, the difference between sitting height values of boys and girls was significant and showed a steady increase until 17 years (Fig. 5).

MUAC values among girls aged 6, 8 and 9 years were marginally higher than for boys; in all other age groups,

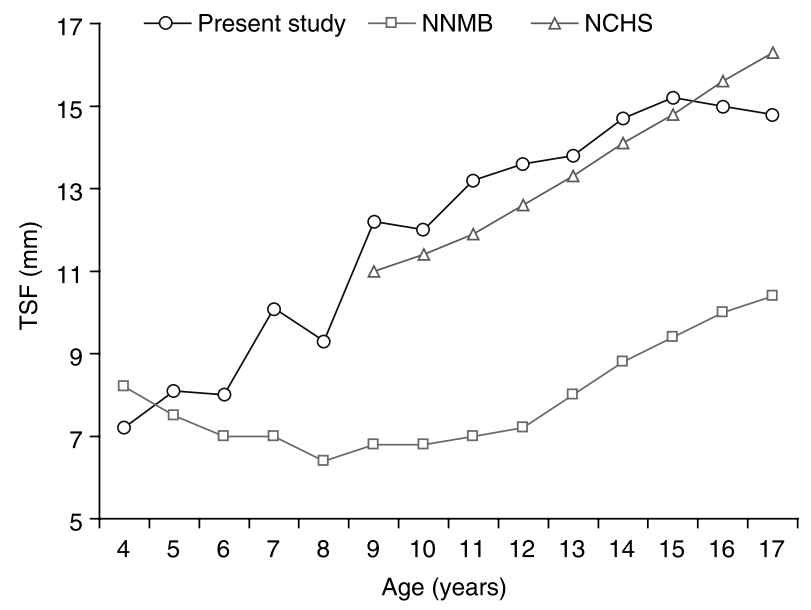

Fig. 8 Comparison of the triceps skinfold thickness (TSF) of affluent girls in the present study with the US National Center for Health Statistics (NCHS) reference and Indian National Nutrition Monitoring Bureau (NNMB) data 
Table 2 Distribution of the study subjects according to weight status based on body mass index

\begin{tabular}{|c|c|c|c|c|c|c|c|c|}
\hline \multirow[b]{3}{*}{ Age (years) } & & & \multicolumn{6}{|c|}{ Weight status } \\
\hline & \multicolumn{2}{|c|}{ Number } & \multicolumn{2}{|c|}{ Normal-weight } & \multicolumn{2}{|c|}{ Overweight } & \multicolumn{2}{|c|}{ Obese } \\
\hline & Boys & Girls & Boys, $n(\%)$ & Girls, $n(\%)$ & Boys, $n(\%)$ & Girls, $n(\%)$ & Boys, $n(\%)$ & Girls, $n(\%)$ \\
\hline $4-5$ & 239 & 186 & $200(83.68)$ & 169 (90.86) & $24(10.04)$ & $9(4.84)$ & $15(6.27)$ & $8(4.30)$ \\
\hline $6-8$ & 412 & 313 & $284(68.93)$ & $232(74.12)$ & $74(17.96)$ & $54(17.25)$ & $54(13.10)$ & 27 (8.62) \\
\hline $9-11$ & 705 & 503 & 449 (63.68) & $306(60.84)$ & $183(25.95)$ & $157(31.21)$ & $73(10.35)$ & $40(7.95)$ \\
\hline $12-14$ & 634 & 492 & $401(63.25)$ & $369(75.00)$ & $197(31.07)$ & $109(22.15)$ & $36(5.67)$ & $14(2.85)$ \\
\hline $15-17$ & 507 & 408 & 377 (74.35) & $343(84.06)$ & $116(22.88)$ & $64(15.68)$ & $14(2.76)$ & $1(0.25)$ \\
\hline Total & \multicolumn{2}{|c|}{$4399(100)$} & \multicolumn{2}{|c|}{$3130(71.15)$} & \multicolumn{2}{|c|}{$987(22.43)$} & \multicolumn{2}{|c|}{$282(6.41)$} \\
\hline
\end{tabular}

boys showed higher values than girls. The difference between the data of boys and girls showed variability, which was greater from age 12 years onwards (Fig. 6). Comparing the present study with the Indian NNMB data, the maximum difference $(7 \mathrm{~cm})$ in the MUAC values was found among boys at 12 and 14 years. This difference in girls was found to be about $6 \mathrm{~cm}$ at 11 years of age. Among all age groups, MUAC values from the present study were higher than corresponding values of the Indian NNMB.

In the present study, TSF values were higher in girls than in boys for all age groups. Boys and girls in the present study had higher TSF values than the Indian NNMB data for all age groups. In the NCHS dataset, TSF values are given only for the age group 9-17 years (Figs 7 and 8). Comparison of the present study data with the corresponding NCHS data showed TSF values to be higher among boys in all age groups in the present study, whereas among girls at ages of 16 and 17 years, the NCHS values were marginally higher.

\section{BMI}

Data on the BMI of all subjects are presented in Table 2. The cut-off points for overweight and obesity recommended by Cole et al. ${ }^{17}$ were used in the present study.

Approximately $22 \%$ of the study children were overweight and $6.4 \%$ were obese. In all age groups, boys were more overweight or obese than girls. In this cross-sectional study, overweight rates were highest in the age group 911 years for girls and 12-14 years for boys.

\section{Birth weight}

Only $6 \%$ of the subjects were of low birth weight $(<2.5 \mathrm{~kg})$ in the present socio-economic group, compared with 33\% in the lower socio-economic group ${ }^{18,19}$. One possible explanation could be that the diets of poor pregnant women are deficient in a variety of nutrients such as $n-3$ fatty acids, iron and zinc. Other factors could be low energy intake, which can lead to low weight gain during pregnancy, infections and smoking.

The majority of children (both boys and girls) with normal BMI had birth weight either $<2.5 \mathrm{~kg}$ or $2.5-3.0 \mathrm{~kg}$ (Figs 9 and 10). The percentage of overweight/obese children increased with increasing birth weight. Subsequent statistical analyses revealed that growth performance was positively correlated with the birth weight of the subject $(P=0.01$, Table 3). Most overweight/obese children had birth weight $\geq 3.0 \mathrm{~kg}$. This trend was found to be more prevalent in boys than in the girls. It was observed that the low birth weight percentage was lower in boys (5.1\%) than in girls (7.2\%). This confirms the prevalence of overweight/obesity being higher in boys than in girls.

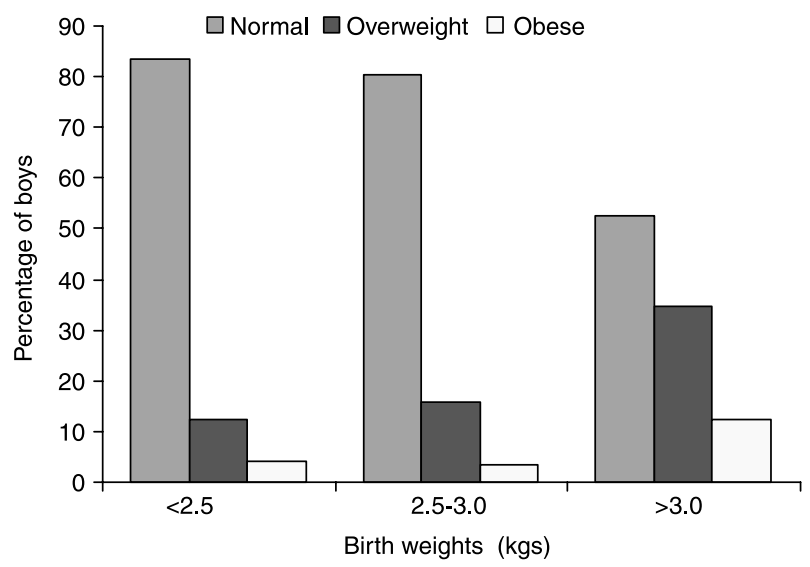

Fig. 9 Percentage of affluent boys in the present study in different categories of birth weight according to current weight status

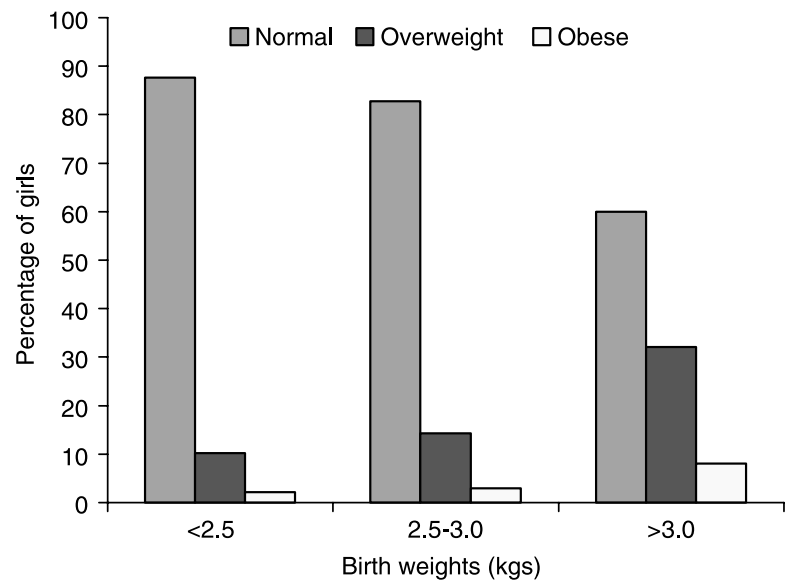

Fig. 10 Percentage of affluent girls in the present study in different categories of birth weight according to current weight status 
Table 3 Correlation between birth weight and present body mass index of the study subjects

\begin{tabular}{lc}
\hline Group & Correlation coefficient \\
\hline Boys & $0.425^{\star \star}$ \\
Girls & $0.329^{\star \star}$ \\
Boys and girls & $0.387^{\star \star}$ \\
\hline
\end{tabular}

${ }^{* *}$ Correlation is significant at the 0.01 level (two-tailed).

\section{Discussion}

Obesity is becoming an increasingly important public health problem affecting all age groups and both sexes. The present study of 4-17-year-olds belonging to the affluent section of Indian society revealed these children/adolescents to have a high prevalence of overweight/obesity. Of the total, 22\% were overweight and $6.4 \%$ were obese. Other studies support our findings related to overweight/obesity among children and adolescents ${ }^{20,21}$. The environmental factors contributing to this are rapid urbanisation and changes in dietary patterns and lifestyles.

More boys were overweight/obese than girls. In both boys and girls, the majority of children with higher BMI were from the middle of the age range; thereafter overweight/obesity rates showed a declining trend with age, which is not normally found. This could be because there was trend for weight to decline and linear growth to level off right after the middle years in this population (as shown by the results of the present study). The decline in weight gain could occur because the children/adolescents become more conscious about their looks with increasing age and restrict their dietary intake, whereas the growth plateau among the NCHS subjects starts at a later age. Hence, the Indians are shorter than their corresponding American counterparts.

Most anthropometric parameters (weight, height, sitting height and MUAC) were higher in boys than in girls for almost all age groups, whereas TSF was found to be higher in girls in all age groups. Of the total (4399) children, only $6 \%$ had low birth weight $(<2.5 \mathrm{~kg})$. The birth weight of these subjects was positively correlated to their present BMI. Children with birth weight $>3.0 \mathrm{~kg}$ were found to have a higher BMI than those who had either low birth weight or birth weight in the category $2.5-3.0 \mathrm{~kg}$.

Thus there is a need to raise awareness not only among children but also parents to reduce the epidemic of high BMI (overweight/obesity), because this is associated with increased cholesterol and blood sugar levels and dyslipidaemias. Dietary excesses should be counteracted with dietary modifications, as even small additions to the diet can increase overall food intake. An earlier study on nutrition and physical exercise education in schools was able to show improvement in indices of fitness and body fat levels ${ }^{22}$, supporting the proposal that physical activity must be stressed in the school environment ${ }^{23}$. This will help in inculcating healthy lifestyles and beneficial dietary habits among children at an early age. This will not only keep them in good shape but will also prevent them carrying health problems into adult life and reduce their likelihood of developing diseases like diabetes, cancer and cardiovascular disease.

\section{Acknowledgements}

We are grateful to Dr C Gopalan, President of the Nutrition Foundation of India, for suggesting this study and for his constant guidance during the study. We are also thankful to the principal, teachers and students of the public school for their cooperation throughout the data collection period.

\section{References}

1 World Health Organization (WHO). Obesity: Preventing and Managing the Global Epidemic. Report of a WHO Consultation. WHO Technical Report Series No. 894. Geneva: WHO, 2000.

2 Shetty P. Secular trends in obesity and physical activity: physiological and public health considerations. In: Shetty P, Gopalan C, eds. Diet, Nutrition and Chronic Disease An Asian Perspective. London: Smith Gordon Publishers, 1998; 89 pp.

3 Gopinath N, Chadha SL, Jain P, Shekhawat S, Tandon R. An epidemiological study of obesity in adults in urban population of Delhi. Journal of Association of Physicians of India 1994; 42: 212-5.

4 Trayhurn P. The biology of obesity - recent developments in the regulation of energy balance. In: Seshadri M, Siddhu A, eds. Nutrition Goals for Asia - Vision 2020. Proceedings of the 9th Asian Congress of Nutrition, New Delhi, India, 2327 February 2003. New Delhi: Nutrition Foundation of India, 2003; 443-7.

5 Krishnaswamy K, ed. Obesity in the Urban Middle Class in Delhi. Scientific Report No. 15. New Delhi: Nutrition Foundation of India, 1999.

6 Misra A, Pandey RM, Devi JR, Sharma R, Vikram NK, Khanna N. High prevalence of diabetes, obesity and dyslipidaemia in urban slum population in northern India. International Journal of Obesity and Related Metabolic Disorders 2001; 25 : 1722-9.

7 Berenson GS, Srinivasan SR, Bao W, Newman WP, Tracy RE, Wattigney WA. Association between multiple cardiovascular risk factors and atherosclerosis in children and young adults. The Bogalusa Heart Study. New England Journal of Medicine 1998; 338: 1650-6.

8 Health implications of obesity. NIH Consensus Statement Online 1985 Feb 11-13; 5(9): 1-7. Available at http://consensus.nih.gov/1985/1985Obesity049html.htm. Accessed 21 December 2004.

9 Agarwal KN, Agarwal DK. Growth - Infancy to Adolescence. New Delhi: CBS Publishers and Distributors, 2003.

10 Booth ML, Wake M, Armstrong T, Chey T, Hesketh K, Mathur S. The epidemiology of overweight and obesity among Australian children and adolescents, 1995-97. Australian and New Zealand Journal of Public Health 2001; 25: 162-9.

11 Torgan C. Childhood obesity on the rise. The NIH Word on Health [online], June 2002. Available at http://www. nih.gov/news/WordonHealth/jun2002/childhoodobesity. htm. Accessed 2 November 2004.

12 Center for Nutrition Policy and Promotion, US Department of Agriculture. Childhood Obesity: Causes \& Prevention. Symposium Proceedings [online], October 1998. Available at http://www.usda.gov/cnpp/Seminars/obesity.PDF\#search = 
$\% 22$ Childhood $\% 20$ obesity $\% 3$ A $\% 20$ Causes $\% 20 \% 26 \% 20$ Prevention. $\% 20$ Symposium $\% 20$ Proceedings $\% 2 \mathrm{C} \% 20$ October \%201998\%2C\%20USDA\%22. Accessed 30 March 2005.

13 Sharma BK. Obesity in childhood can lead to diabetes. The Tribune, 21 April 2002.

14 Jelliffe DB, Jelliffe EFP, Zerfas A, Neumann CG. Community Nutritional Assessment with Special Reference to Less Technically Developed Countries. Oxford: Oxford University Press, 1989.

15 World Health Organization (WHO). Measuring Change in Nutritional Status. Guidelines for Assessing the Nutritional Impact of Supplementary Feeding Programmes for Vulnerable Groups. Geneva: WHO, 1983.

16 National Nutrition Monitoring Bureau (NNMB). Diet and Nutritional Status of Rural Population. NNMB Technical Report No. 21. Hyderabad: National Institute of Nutrition, Indian Council of Medical Research, 2002.

17 Cole TJ, Bellizzi MC, Flegal KM, Dietz WH. Establishing a standard definition for child overweight and obesity worldwide: international survey. British Medical Journal 2000; 320: 1240-3.

18 Gopalan C. Multiple micronutrient supplementation in pregnancy. Nutrition Reviews 2002; 60: S2-S6.

19 Gupta AK, Ahmad AJ. Childhood obesity and hypertension. Indian Pediatrics 1990; 27: 333-7.

20 De Onis M, Blossner M. Prevalence and trends of overweight among preschool children in developing countries. American Journal of Clinical Nutrition 2000; 72: 1032-9.

21 Vijaylakshmi K, Reddy GA, Krishna TP, Krishnaswamy K. Obesity in adolescents of different socio-economic groups: prevalence in Andhra Pradesh, India. Asia Pacific Journal of Clinical Nutrition 2002; 11: S742-3.

22 Epstein LH. Effects in treatment of childhood obesity. International Journal of Obesity and Related Metabolic Disorders 1995; 19: S117-21.

23 Shetty P. Childhood obesity in developing countries. NFI Bulletin 1999; 20: 1-4. 